\title{
Participation after Stroke and Traumatic Brain Injury: Results of a Pilot Study in Outpatient Neurorehabilitation in Vorarlberg
}

\section{(0)(1) $\circledast$}

\author{
Authors \\ Dominik Pöppl ${ }^{1}$, Judith Marheineke ${ }^{2}$, Ruth Deck ${ }^{3}$ \\ Affiliations \\ 1 St. Elisabeth Hospital, Geilenkirchen \\ 2 Outpatient Rehabilitation in Geilenkirchen Hospital \\ 3 Institute for Social Medicine, Luebeck University \\ Key words \\ traumatic brain injury, measurement of outcomes, stroke, outpatient \\ neurological rehabilitation \\ Bibliography \\ DOI http://dx.doi.org/10.1055/s-0043-102390 \\ Neurology International Open 2017; 1: E71-E78 \\ (c) Georg Thieme Verlag KG Stuttgart · New York \\ ISSN 2511-1795 \\ Correspondence \\ Dominik Pöppl \\ Outpatient Rehabilitation \\ Martin-Heydenstr. 32 \\ 52511 Geilenkirchen \\ d.poeppl@reha-geilenkirchen.de
}

\section{ABSTRACT}

Objective A multicentric study has reported on the sustained effects of outpatient neurorehabilitation in Germany. Different to Germany, the biopsychosocial model of disability, as described in the International Classification of Functioning, Disability and Health (published by the World Health Organization), is not incorporated into Austrian law. There is a need for objective measurement instruments for routine outcome evaluation of outpatient neurorehabilitation in Austria. The present examines the extent to which the instruments used for the German multicentric study are applicable in the Austrian rehabilitation context and if there are similar rehabilitation effects over time.

Method In a multicentric observational study, patients of 4 Austrian outpatient neurorehabilitation centers for stroke or traumatic brain injury were asked to fill in a questionnaire. This was carried out 4 times throughout the program: on admission and discharge as well as on month 4 and 12 post rehabilitation. Additionally, clinical experts were asked to rate the patients' status at admission and discharge.

Results and conclusions The results of 4 outpatient neurorehabilitation centers in Vorarlberg (Austria) suggest that the used measurement instruments are reasonable for the evaluation of outpatient neurorehabilitation in Austria, based on the ultimate goal "participation and self-determined conduct of life". For routine outcome evaluation, fewer instruments should be used and adjustments should be made while assessing more severely affected patients.

\section{Introduction}

Stroke is the third most common cause of death worldwide and one of the most common causes of permanent disability and a major cost factor in health care systems [1]. According to the Federal Ministry of Health, about 20000 people in Austria suffer an ischaemic stroke every year. The lifetime prevalence for ischaemic and haemorrhagic stroke is estimated to be around $2 \%$ in Austria. After acute treatment and rehabilitation, about a quarter of the surviving patients have severe disability [2]. Among the most common functional disorders are persistent impaired physical, cognitive and affective abilities, as well as disturbances of sensory perception. In addition to limited mobility, communication impairments and cognitive impairments, development of depressive symptoms in stroke patients represents a major problem since it can hinder rehabilitation and reintegration $[3,4]$.

In Germany, the bio-psycho-social model of functional health, on which the International Classification of Function and Disability (ICF) published by the World Health Organization (WHO) is based, is firmly anchored in German social law and designates participation and self-determined conduct of life of patients as the most important tasks of rehabilitation. The German health insurers explicitly demand an implementation of the ICF concept in all institutions approved by them. Unlike in Germany, the ICF model is not explic- itly anchored in Austria. However, in 1992, the Austrian Federal Government adopted a disability concept developed jointly with the Austrian Working Group of Rehabilitation for ensuring that patients acquire the best possible participation skills after rerhabilitation [5].

Therefore, the concept of participation oriented to the ICF and the UN Disability Equality Convention can also be regarded as the key target for rehabilitation success in Austria. As described elsewhere [6], in neurological rehabilitation in Germany, especially the facilities of outpatient/semi-inpatient neurological rehabilitation endeavoured to approach the participatory construct because they were in close vicinity to the living and working world of the patients. In Austria, ICF and participation-oriented neurological rehabilitation still has a model character. Documented model tests are carried out in Carinthia and Vorarlberg [7-9]. Although the goal of outpatient neurorehabilitation in Austria is similar to that in Germany, there are some significant differences in its implementation. The duration of treatment is significantly longer, the treatment can be tailored more specifically to the needs of the patients (for example, treatment received only from some specific medical specialties) and rehabilitation is not managed by a doctor. Compared to Germany, therefore, there is no clear line between complex rehabilitation and the provision of medicinal products. 
In reviewing the effectiveness of participation-oriented rehabilitation, ultimately the impact of rehabilitation measures on the actual participation abilities of the rehabilitants must be recorded. To date, however, there is no consensus on appropriate instruments to measure participation objectively, reliably and validly. The lack of operationalization of the concept of participation is considered as the main cause of this dissent $[10,11]$. In any given clinical case, ICF coding of participation impairment is often very difficult and complex. The idea of disease-specific core sets [12] has not yet established itself in clinical practice. Accordingly, there are only a few studies in German-speaking world that include participation as a central outcome variable.

In a German multicentric project in a near-home ambulatory rehabilitation centre [6,13-17], the combined use of different measuring instruments enabled adequate recording and evaluation of participation-related effects. Of particular relevance were, among others, the interdisciplinary index for the measurement of restrictions on participation (IMET) [18] and the independent index for neurological and geriatric rehabilitation (SINGER) [19-21]. At the same time, the results published to date clearly indicate positive and lasting effects of outpatient neurological rehabilitation in Germany.

The aim of the present study was to investigate whether the instruments used in the above-mentioned German study are also suitable in the Austrian rehabilitation context, and whether near-home outpatient rehabilitation in Vorarlberg neurorehabilitation facilities lead to similar results in the sense of enabling patients to reach a level of independence that allows participation and leading of independent life. These were measured over several time points.

\section{Methods}

The data presented here were collected in an exploratory multicentric observation study with a longitudinal design in 4 ambulatory neurological rehabilitation facilities run by Sozialmedizinische Organization Neurologische Rehabilitation $\mathrm{GmbH}(\mathrm{SMO})$ in the Austrian province of Vorarlberg. In the study, within a defined period of investigation, patients undergoing rehabilitation after stroke or craniocerebral trauma were asked to fill in questionnaires at 4 time points (at the beginning, at the end, and 4 and twelve months after completion of the outpatient neurorehabilitation program). In addition, patient status at the beginning and at the end of the rehabilitation measures was assessed by treating physicians. The survey was carried out between February 2012 and March 2014.

\section{Inclusion and exclusion criteria}

In the sample, all neurological rehabilitation patients with stroke (ischaemia, intracerebral haemorrhage or non-traumatic subarachnoid haemorrhage) or traumatic brain injury in the neurological rehabilitation phases $\mathrm{D}$ and $\mathrm{E}$ were consecutively included in the study. A written declaration of consent for participation in the study was obtained. Patients receiving fewer than 11 therapies were excluded, since in these cases, no relevant therapy effects are to be expected. Patients with advanced dementia and patients with severe aphasia or alexia were not included because of their limited judgment or communication disability. Physicians and neuropsychologists of the participating institutions carried out this assess- ment. Patients with presumably diminished or even completely absent awareness of their illness were not excluded from participation. Rehabilitants, who were treated far from their homes, in the sense that during treatment, they were not living at home, however, were not included in the sample, since this is rarely found in the outpatient rehabilitation concept and is possibly only in some special cases of offers from some rehabilitation centres. In order to distinguish rehabilitation measures from medication therapy, and to compare our results with the programme of multiprofessional neurological complex rehabilitation in Germany, only those rehabilitants were included with treatment needs in at least 2 specialist areas.

\section{Implementation and procedure}

In the participating institutions, patient recruitment was started with on-site training of staff by the director of the overall study. In addition, a regional study coordinator was appointed. Furthermore, a 7-member advisory board was set up consisting of the director of studies and representatives of the cooperating institutions, who continued to guide and support the study. The study was carried out according to the detailed study protocol of a previous study [13].

\section{Data protection}

Compliance with data protection regulations was ensured at all times during the survey. The participating rehabilitants agreed in writing to participate in the study and use of the collected data.

\section{Instruments}

All subjects were given a comprehensive questionnaire with a total of up to 13 different assessment instruments depending on the time-point of assessment. In the following, only the instruments relevant to the present study will be specified. Data on sociodemographic and socio-medical indicators were gathered according to Deck et al. [22]. The Index for Measuring Restrictions on Participation (IMET) is a self-assessment instrument for recording patient participation [14, 18]. The SINGER, as a third-party assessment instrument, gathers data on independence in important aspects of daily life [16, 19-21]. In addition, the phase to which rehabilitants belong can be determined using the SINGER total score model, a system established firmly in the Phase model [23] of neurorehabilitation of the Association of German Pension Insurances (now Deutsche Rentenversicherungsbund) [24]. The subjective perception of general state of health was investigated with a 5-point scale. The subjective performance in everyday life, leisure and work was assessed by means of three 11-point rating scales. The EQ-5D instrument was used to record the health-related quality of life of the rehabilitants $[25,26]$. The severity of the stroke at the start of rehabilitation was assessed using the modified Rankin Scale (mRS) of Banks and Marotta [27]. The Glasgow Coma Scale (GCS) is a scale for estimating consciousness disorders after a brain injury [28]. This scale is used for assessing the severity of injury in the acute phase.

\section{Analysis}

All calculations were performed with SPSS 18. SRM was used to determine the effect size for the SINGER data [29]. According to Cohen [30], effects of $d=0.2$ are small, of $d=0.5$ medium and of $\mathrm{d}=0.8$ large effects. In the preparation of the data, missing item 
values were replaced by the mean value of the variables in accordance with the recommendations of Wirtz [31] and Schafer and Graham [32], respectively, if no more than $30 \%$ of the values were missing in a particular case. Otherwise, the case was excluded. For the investigation of frequency differences in the occurrence of certain features or feature combinations, $X^{2}$ methods were applied and Friedman tests were carried out for the purpose of testing mean-value differences [33]. For a comparison of the SINGER data as a linked sample, a t-test for dependent samples was performed. The recommendations of Faller et al. [34] of an $\alpha$-error level of $5 \%$ was chosen for all calculations.

\section{Intervention}

All rehabilitants were treated according to the concept of SMO Neurological Rehabilitation [7]. It can be assumed that treatment was uniform (treatment integrity) in all the participating SMO facilities. All rehabilitants received weekly therapies from at least 2 medical specialties over the entire treatment period. Therapies were offered at least 3-5 days per week and the total therapy time was $6-15 \mathrm{~h}$ per week (including music therapy). After 12 therapies, a therapy target evaluation was carried out, whereupon the treatment could be optionally extended by 6 weeks.

\section{Results}

The observation period was between August 2013 and August 2015. In the recruitment period from August 2013 to May 2014, out of 163 patients enrolled for rehabilitation in the participating institutions, 39 rehabilitants (stroke patients: $n=38$; patient after a traumatic brain injury: $n=1$ ) could be included as study participants. The sample flow is illustrated in $>$ Fig. 1 . The return rate for the 4-month follow-up was $72 \%(n=28)$ and the 12 -month follow-up was $56 \%(n=22)$.

The distribution of the sociodemographic and socio-medical indicators of the random sample is shown in > Table 1 . The severity of impairment in stroke patients averaged $2.76(S D=1.03)$ on the mRS, which can be classified between mild and moderate severity. The GCS value of the rehabilitants after traumatic brain injury was 15 , which represents a mild injury in the acute phase.

The changes in the collected outcome parameters general health, participation, performance in everyday life, leisure and work as well as health-related quality of life, were examined by means of Friedman tests. The results are shown in $>$ Table 2 . There were significant changes over time on the scales of general health and performance in everyday life. From a purely descriptive point of view of the change in the scores over time, there was improvement across all scales during the rehabilitation period. In the follow-up period, the values on all scales came close to the initial values again but did not reach them. Assessment of professional performance was an exception, but data on only 2 persons are available. Due to the central importance of participation changes, the IMET values over time are displayed in $>$ Fig. 2.

The changes in the IMET values at the level of individual items are listed in $>$ Table 3 , the changes in the summed scores are shown in $>$ Fig. 3. The mean values of the individual item scores of the IMET showed over time the same changes over the investigation period. The participation status improved during the rehabilitation

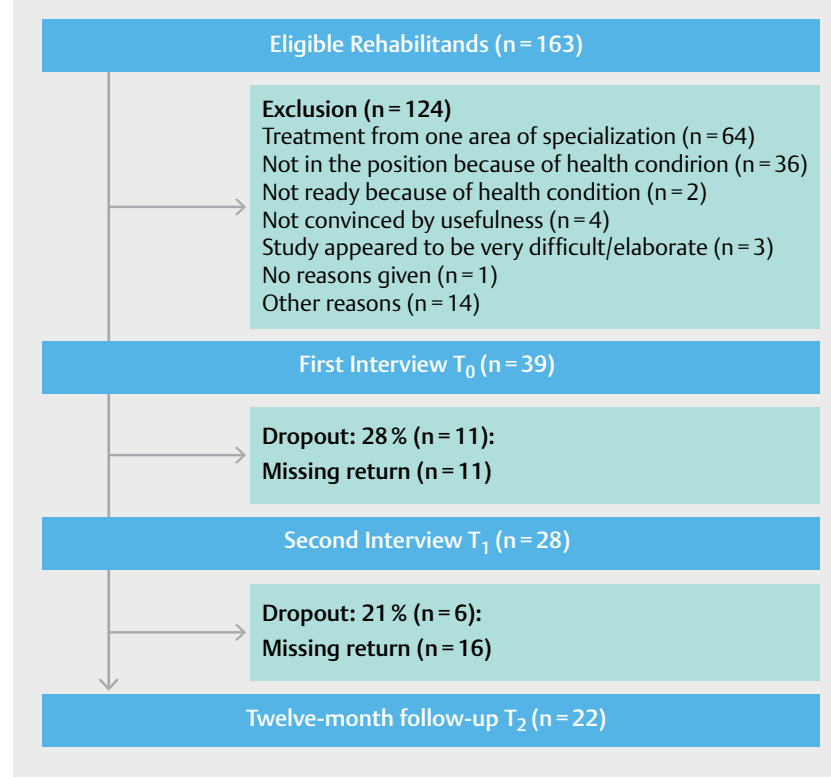

- Fig. 1 Flow chart of the study.

- Table 1 Overview of the sociodemographic and socio-medical indicators of the participants.

\begin{tabular}{|c|c|}
\hline & participants \\
\hline \% Gender Male & 59.0 \\
\hline MW (SD) Age & $62.1(12.8)$ \\
\hline MW (SD) Treatment duration in days & $102.7(47.4)$ \\
\hline MW (SD) Days of therapy & $30.2(17.5)$ \\
\hline \% Diagnosis Ischaemia & 71.8 \\
\hline \% Rehabilitation in release from hospital & 46.2 \\
\hline \% Rehabilitation after acute event & 82.2 \\
\hline \% Statutory health insurance & 41.0 \\
\hline $\begin{array}{l}\text { \% Highest education level Lower secondary7 } \\
\text { Elementary school }\end{array}$ & 44.7 \\
\hline \% Completed occupational training & 81.6 \\
\hline \multicolumn{2}{|l|}{ Employment status } \\
\hline \% Full-time employment & 16.2 \\
\hline \% Retired & 51.4 \\
\hline \% Job status Employee/worker & 55.9 \\
\hline$\%$ Net income family $>2000 € /$ Monat & 47.4 \\
\hline MW = Mean value; $S D=$ Standard deviation & \\
\hline
\end{tabular}

period and stabilized during the follow-up period with a slight worsening of the mean values compared to the values at the end of rehabilitation. In the case of the 4 items, namely activities of daily life, family and domestic commitments, as well as recreation and leisure, there appeared to be a worsening of the participation status during the time period from the end of rehabilitation to 4 months after rehabilitation; thereafter, there was an improvement up to the period of twelve months after rehabilitation. For all items, 


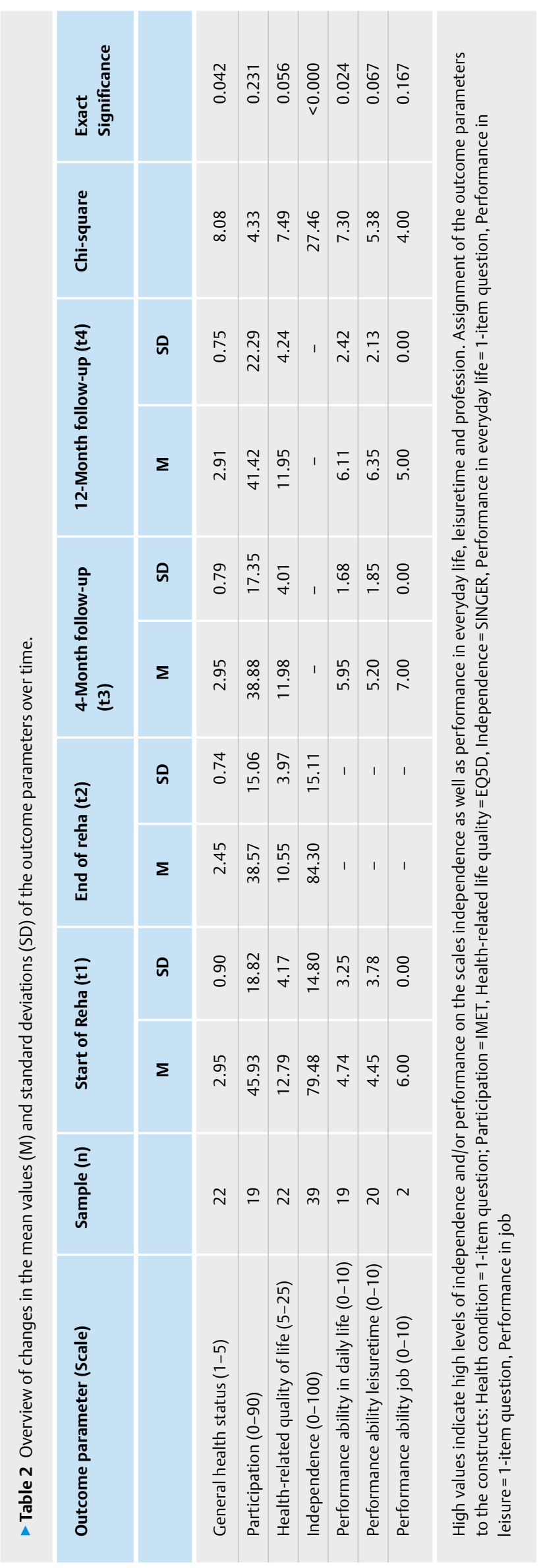

except for sex life, improved participation was observed over the entire observation period from start of rehabilitation to 12 months after its completion. In the items common activities of daily life and close personal relationships, impairments were the lowest at the beginning of rehabilitation; the highest initial impairments were seen in the items recreation and leisure. At the 12-month follow-up, the scores of the 6 items, namely common activities of daily life, family and domestic obligations, tasks outside of home, daily tasks and commitments, recreation and leisure, as well as social activities, were lower than those at the end of rehabilitation.

For the changes in independence, measured in the expert rating with the SINGER, the complete data set of $n=39$ rehabilitants were available for analysis. A total of $\mathrm{n}=12$ rehabilitants had an initial SINGER sum score less than 74 and could be assigned to neurological phase $C$. In a t-test for dependent samples, the mean value differences reached statistical significance at both time points of measurement, $t(38)=-5.580 ; P<0.001$. The post hoc calculated effect was dpre-post $=0.32(1-\beta=0.99)$.

The results of the third-party SINGER values are shown in - Table $\mathbf{4}$ according to the ICF chapter Activities and Participation d1-d9 of the SINGER. Overall, there was improvement in all areas during the rehabilitation period. The area of participation which showed the best values both at the beginning and end of the rehabilitation process and also that showed the least number of changes during this period is that of communication. The lowest numerical improvements were found in interpersonal interactions and relationships. The participation area with regard to domestic life showed the worst values at the beginning and end of the rehabilitation period, but from all areas covered, improvement here was the strongest.

\section{Discussion}

The regulatory framework for neurorehabilitation in Austria has advantages and disadvantages compared to the framework conditions in Germany. The resources available in the Vorarlberg facilities investigated in this study exceed those available in most German institutions in terms of therapeutic frequency and duration. The model has been developed without any inter-carrier framework conditions such as the BAR framework recommendations. This requires enormous preliminary and development work by operators of rehabilitation facilities. The rehabilitation facilities financed primarily by social funds in Vorarlberg according to the model of the institutions examined here places very high demands on access to the rehabilitation market, which makes the admission of other providers to the market and thus provision of even more extensive rehabilitation care scarcely possible. The rehabilitation landscape in Austria is far more heterogeneous compared to Germany. The rehabilitation model investigated here allows for the appropriate use of therapy by different medical professions, which is a clear advantage. Research and development of rehabilitation occupies a larger area in Germany, and further development is easier to implement through comparable framework conditions for the rehabilitation facilities, and is more easily available with less own development work. Overall, the conditions of neurorehabilitation in Germany and Austria are not very comparable. 
The results of our sample of 4 outpatient neurological rehabilitation centres run by one carrier in the Austrian province of Vorarlberg presented here show that, despite the divergent rehabilitation contexts, the instruments employed in the course of a large multicentre study that included 17 German outpatient rehabilitation facilities [6,13-17] can be meaningfully used for outcome evaluation in the Austrian context. During data collection and analysis, there was no evidence for a limited applicability of the instruments in the Austrian context. Comparison of the reported sociodemographic and socio-medical indicators of the study participants and the key figures of the similarly designed and carried out multicentric study in Germany [6,13-17] show similarities and differences between the study populations. In all of our own and comparable studies, there was a high scatter in participation impairments; this can also be observed in a healthy population. The IMET values over time also showed very similar trajectories in our own and comparable studies. There are no indications that these were significantly influenced by the dropout rate.

In contrast to most rehabilitants in Germany, the Vorarlberg patients were treated significantly longer and received a larger number of therapies. In contrast to the inclusion criteria, the proportion of rehabilitants with phase $C$ disease was also one-third higher than

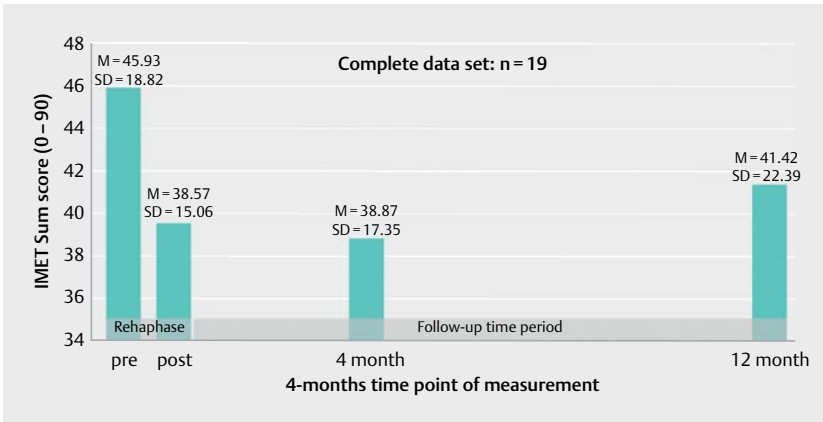

- Fig. 2 IMET-scores of participants over time. in those in the outpatient neurorehabilitation in Germany. In a study of the structures and processes in the ambulatory neurorehabilitation in Germany [15], only $18 \%$ of the institutions surveyed reported that they had a small proportion of phase $C$ rehabilitation patients. In the already mentioned multicentre study, the proportion of rehabilitants in phase $C$ at the start of rehabilitation, as determined by the SINGER total score, was $5 \%$ (unpublished result). Thus, there are clear differences in the framework conditions of outpatient neurorehabilitation in Germany and Austria, which need a more detailed investigation. Despite the very similar approach to data collection in the 2 countries, the results are comparable only to a very limited degree. The authors of this study are currently preparing a work on the different framework conditions of outpatient neurorehabilitation in Austria and Germany. However, despite the severity of impairments of rehabilitants, the results show an improvement in their participation abilities over the course of rehabilitation. In Germany, the possibility of adequately treating phase $C$ rehabilitants in near-home outpatient neurorehabilitation facilities has already been demonstrated in a larger sample [35].

The results of the present study suggest that positive and lasting results are achieved within the framework of the Vorarlberg near-home ambulatory rehabilitation in the sense of promoting participation and self-determined life-style. Over almost all of the parameters on which data were collected, there were positive effects in the course of the rehabilitation period, which was on average about 15 weeks. The significance is limited by the low sample size and the resulting low statistical power of the data.

Short-term positive rehabilitation effects are to be expected in principle because they have already been shown to occur over many outcome variables in many different areas and forms of rehabilitation in Germany [36].

In a previous similar multicentre study carried out in ambulatory neurorehabilitation in Germany [6], similar developments in improvement were observed over the entire observation period. In Austria, an improvement was seen across various outcome para-

Table 3 Overview of the descriptive changes of the mean values (M) and standard deviations (SD) of the IMET values at the item level for the entire sample over the time course of rehabilitation.

\begin{tabular}{|c|c|c|c|c|c|c|c|c|}
\hline \multirow[t]{2}{*}{ IMET Items (Scale 0-9) } & \multicolumn{2}{|c|}{ Reha start (t1) } & \multicolumn{2}{|c|}{ Reha end (t2) } & \multicolumn{2}{|c|}{ 4-Month follow-up (t3) } & \multicolumn{2}{|c|}{ 12-Month follow-up (t4) } \\
\hline & M & SD & M & SD & M & SD & M & SD \\
\hline Activities of daily life & 4.47 & 2.54 & 3.58 & 2.23 & 3.79 & 2.38 & 3.00 & 2.10 \\
\hline Family and domestic tasks & 6.87 & 3.24 & 5.87 & 3.03 & 6.11 & 2.60 & 5.70 & 2.21 \\
\hline Tasks outside the house & 6.47 & 3.51 & 6.35 & 2.94 & 5.89 & 3.11 & 5.00 & 2.94 \\
\hline Daily duties and tasks & 6.97 & 3.27 & 5.87 & 2.97 & 5.64 & 2.94 & 5.10 & 2.42 \\
\hline Recreation and leisure & 7.45 & 2.82 & 5.37 & 2.68 & 6.12 & 2.64 & 5.35 & 2.09 \\
\hline Social activities & 5.51 & 3.44 & 4.90 & 2.95 & 4.56 & 2.37 & 3.80 & 2.03 \\
\hline Close personal relationships & 3.78 & 3.28 & 2.63 & 2.51 & 2.75 & 2.28 & 2.75 & 1.68 \\
\hline Sex life & 6.47 & 3.40 & 5.94 & 3.62 & 6.67 & 2.94 & 6.68 & 2.40 \\
\hline Stress and extraordinary stress & 5.89 & 3.22 & 4.49 & 2.91 & 4.96 & 2.48 & 5.21 & 2.24 \\
\hline
\end{tabular}




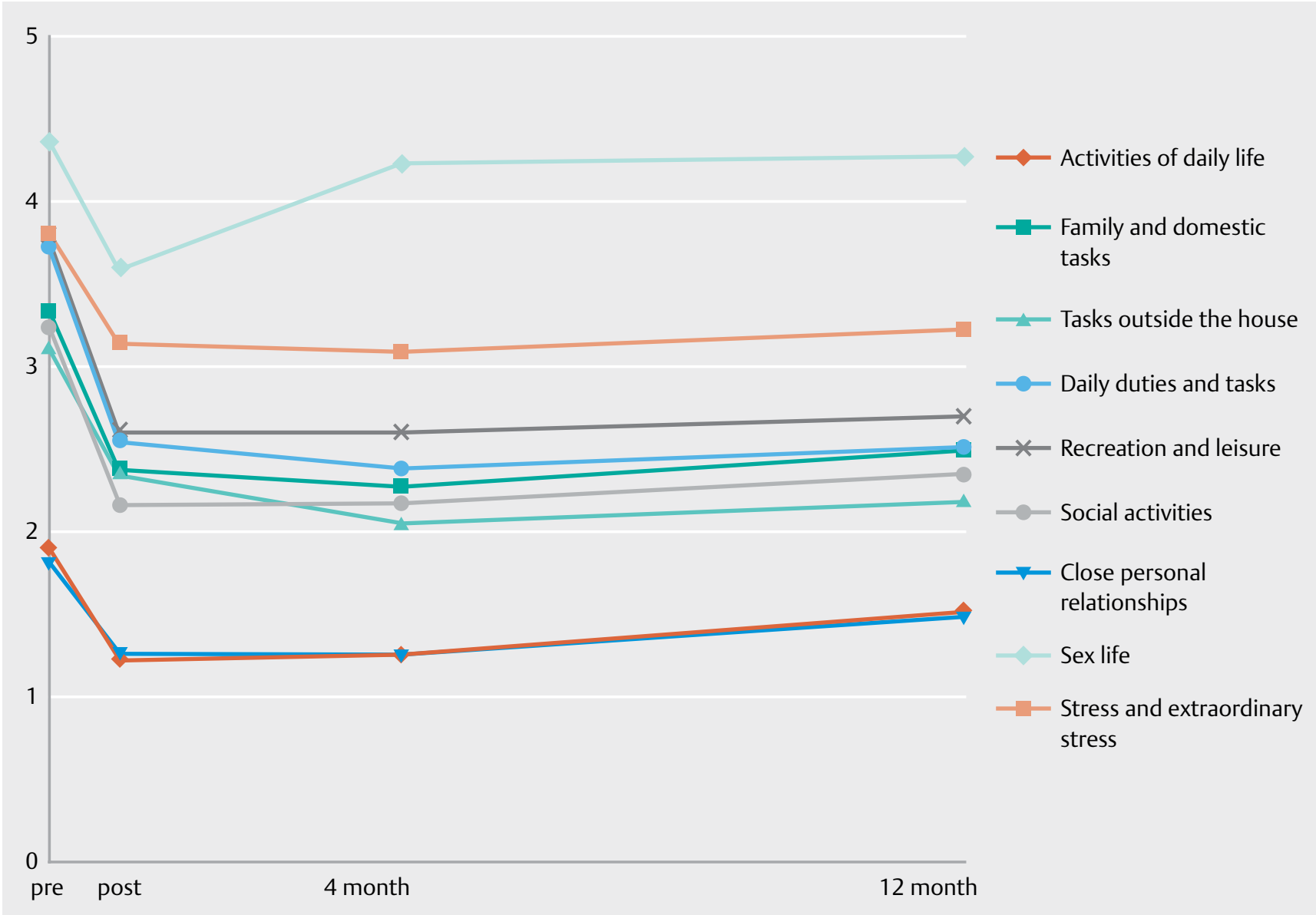

Fig. 3 IMET Scores at item level over time.

- Table 4 Changes in participation and activities over time assigned according to SINGER-scores of rehabilitants at the item level.

\begin{tabular}{|l|l|l|l|l|}
\hline $\begin{array}{l}\text { ICF-chapter } \\
\text { (Scale } \mathbf{0 - 5 )}\end{array}$ & \multicolumn{2}{|c|}{ Reha start (t1) } & \multicolumn{2}{|c|}{ Reha end (t2) } \\
\hline & M & SD & M & SD \\
\hline $\begin{array}{l}\text { d1 Lerning and use of } \\
\text { knowledge }\end{array}$ & 3.91 & 0.71 & 4.15 & 0.70 \\
\hline d3 Communication & 4.51 & 0.55 & 4.60 & 0.52 \\
\hline d4 Mobility & 3.83 & 1.23 & 4.14 & 1.15 \\
\hline d5 Self care & 3.99 & 0.99 & 4.25 & 0.96 \\
\hline $\begin{array}{l}\text { d6 Domestic life } \\
\text { d7 Interpersonal }\end{array}$ & 1.84 & 1.73 & 2.42 & 1.77 \\
\hline $\begin{array}{l}\text { interactions and } \\
\text { relationships }\end{array}$ & 4.64 & 0.63 & 4.72 & 0.56 \\
\hline
\end{tabular}

High values indicate high levels of indpendence

meters over the duration of rehabilitation and was maintained in the follow-up period. This also applied to participation areas that received special attention. There were few deviations from the Ger- man data. On average, however, the Vorarlberg rehabilitants had significantly more severe impairments at the time of starting rehabilitation in relation to all outcome parameters. In Germany and Austria, rehabilitants with impairments of different degrees of severity seek outpatient rehabilitation. In this context, the relatively low number of study participants appears to be plausible, despite a rather long recruitment period. In addition, the extensive set of questionnaires was overwhelming for many rehabilitants and the inclusion criteria were not met due to the severity of the disease. In addition, compared to Germany, rehabilitants in the Vorarlberg facilities are given treatment over a very long period, which meant that the pool of new patients starting rehabilitation from which study subjects could be recruited was relatively small. Due to the small sample size, no broader clinical implications from the data reported are drawn.

Compared to previous studies [37], data gathering on explicitly participation-related outcomes is new for Austria. To date, there are no publications on this subject. In summary, participation-oriented healthcare research and measurement of results can provide a bridge to the relevant daily life of rehabilitants and reveal essential areas for rehabilitation and follow-up care. However, the number of assessment instruments is large so that they have only limited applicability in routine use for acquisition of data on results of rehabilitation. The extent of the survey can be overwhelming for severely ill persons, so that it is necessary to reduce the number of 
instruments used for data gathering; the smaller number, however, is sufficient for the purpose in this context. It would also be desirable to carry out third-party assessment during the follow-up period. With regard to the assessment of participation status, a comparison with population-related data is also possible in the future as described recently by Deck et al. [38]. The use of the SINGER and the IMET appears to be meaningful. The good practical and psychometric properties allow for a valid quantifying examination and a comprehensible description of changes in participation disorders and are to be preferred to purely heterogeneous descriptions of participation impairments in rehabilitants.

\section{Limitations}

The small sample size limits interpretability of the results [39]. No general statements on the efficacy of outpatient neurorehabilitation carried out in Vorarlberg are possible, since, for example, spontaneous remissions or a regression to the average could not be detected and, in particular, a control group was missing. The examined sample is quite heterogeneous, but corresponds to a cross-section of the typical rehabilitation clientele under regular care. However, pilot studies in healthcare research with a descriptive character can be regarded as an important preliminary work for further studies.

\section{Key message}

The results presented here of a sample of 4 outpatient neurological rehabilitation centres in the Austrian province of Vorarlberg suggest that with the instruments used, meaningful assessment of participation as an outcome of rehabilitation can be carried out. For routine use, a smaller selection of evaluation instruments adapted for severely affected rehabilitants is offered.

\section{Funding}

Study material was gathered within the framework of a multicentric investigation [6, 12-16] under the auspices of BV ANR e.V., with funding from the participating institutions of BV ANR e.V., the CNS - Hannelore Kohl Foundation and the Federal Association Neurorehabilitation (BNR). The analysis and evaluation of data reported here was financed by the operators of the investigated facilities.

\section{Conflict of Interest}

The authors declare they have no conflict of interests. Funding for the study did not influence data analysis and interpretation.

\section{References}

[1] Johnston SC, Mendis S, Mathers CD. Global variation in stroke burden and mortality; estimates from monitoring, surveillance, and modelling. Lancet Neurol 2009; 8: 345-354

[2] Busch MA, Schienkiewitz A, Nowossadeck E et al. Prävalenz des Schlaganfalles bei Erwachsenen im Alter von 40 bis 79 Jahren in Deutschland. Bundesgesundheitsbl 2013; 56: 656 -660
[3] Schneider K, Heise M, Heuschmann P et al. Lebens- und Versorgungssituation von Schlaganfallpatienten. Nervenheilkunde 2009; 28: 114-118

[4] Huff W, Steckel R, Sitzer M. „Poststroke Depression“ - Epidemiologie, Risikofaktoren und Auswirkungen auf den Verlauf des Schlaganfalls. Nervenarzt 2003; 74: 104-114

[5] Bundesministerium für Arbeit, Soziales und Konsumentenschutz. UN-Behindertenrechts-Konvention. Erster Staatenbericht Österreichs. Wien: BMASK; 2010: 1-60

[6] Pöppl D, Fries W, Deck R et al. Teilhabe nach Schlaganfall: Ergebnisse einer multizentrischen Katamnesestudie in der ambulanten Neurorehabilitation (Teil 1). Akt Neurol 2016; 43: 7-13

[7] Girardi P, Acherer E, Holzapfl M. Ambulante, interdisziplinäre Teamarbeit im Spannungsfeld zwischen Theorie und Praxis - die Sozialmedizinische Organisation in Vorarlberg. Rehabilitation 1998; 37: 229-232

[8] Mairhofer H. Anwendung der ICF in Österreich. Im Internet: http:// www.dgrw-online.de/files/mairhofer.pdf Stand: 09.12.2015

[9] Ludwig Boltzmann Institut. Ambulante neurologische Rehabilitation: Erreichung der definierten Ziele bei SchlaganfallpatientInnen. Im Internet: http://eprints.hta.lbg.ac.at/1071/1/DSD_92.pdf Stand: 17.07.2016

[10] Dijkers MP. Issues in the conceptualization and measurement of participation: an overview. Arch Phys Med Rehabil 2010; 91 (9 Suppl.): 5-16

[11] Farin E. Konzeptionelle und methodische Herausforderungen der Teilhabeforschung. Rehabilitation 2012; 51 (Suppl 1): 3-11

[12] Ewert T, Geyh S, Grill E et al. Die Anwendung der ICF in der Neurorehabilitation anhand des ICF-Modellblattes und der ICF Core-Sets. Neurol Rehabil 2005; 11: 179-188

[13] Pöppl D. Evaluation der Ergebnisqualität in der wohnortnahen ambulanten Neuro-Rehabilitation unter besonderer Berücksichtigung des sozialgesetzlich verankerten Rehabilitationsauftrages zu Teilhabe und selbstbestimmter Lebensführung - Eine multizentrische Beobachtungsstudie mit einjähriger Katamnese. 2012; Im Internet http://www.bv-anr.de/120829-Studie-EvaluationderErgebnisqualitaet. pdf Stand: 19.01.2012

[14] Pöppl D, Deck R, Fries W et al. Messung von Teilhabe in der wohnortnahen ambulanten Neurorehabilitation - eine Pilotstudie. Fortschr Neurol Psychiatr 2013; 81: 570-578

[15] Pöppl D, Deck R, Kringler W et al. Strukturen und Prozesse in der ambulanten Neurorehabilitation. Rehabilitation 2014; 53: 168-175

[16] Pöppl D, Deck R, Gerdes N et al. Eignung des SINGER als Assessment-Instrument in der ambulanten neurologischen Rehabilitation. Rehabilitation 2015; 54: 22-29

[17] Pöppl D, Deck R, Fries W et al. Ist die Erfassung und Beachtung von Resilienz als personbezogener Kontextfaktor in der ambulanten Neurorehabilitation sinnvoll? Akt Neurol 2014; 41: 335-342

[18] Deck R, Mittag O, Muche-Borowski C et al. Index zur Messung von Einschränkungen der Teilhabe (IMET) - Erste Ergebnisse eines ICF-orientierten Assessmentinstruments. Praxis Klin Verhaltensmed Rehabil 2007; 76: 113-120

[19] Gerdes N, Funke UN, Schüwer U et al. Ergebnisorientierte Vergütung der Rehabilitation nach Schlaganfall - Entwicklungsschritte eines Modellprojekts 2001-2008. Rehabilitation 2009; 48: 190-201

[20] Gerdes N, Funke UN, Schüwer U et al. „Selbständigkeits-Index für die Neurologische und Geriatrische Rehabilitation (SINGER)“ - Entwicklung und Validierung eines neuen Assessment-Instruments. Rehabilitation 2012; 51: 289-299

[21] Funke N, Schüwer U, Themann P et al. SINGER Manual zur Stufenzuordnung. Regensburg: Roderer; 2009 
[22] Deck R, Röckelein E. Zur Erhebung soziodemographischer und sozialmedizinischer Indikatoren in den rehabilitationswissenschaftlichen Forschungsverbünden. In: Verband Deutscher Rentenversicherungsträger., (Hrsg.). Förderschwerpunkt „Rehabilitationswissenschaften“ - Empfehlungen der Arbeitsgruppen „Generische Methoden“, „Routinedaten“ und „Reha-Ökonomie“.1999: 84-102 Im Internet http://www.deutsche-rentenversicherung.de/nn_10540/ SharedDocs/de/Inhalt/Zielgruppen/01__sozialmedizin_ forschung/03_reha__wissenschaften/dateianhaenge/empfehlung__ pdf,templateld $=$ raw, property $=$ publicationFile.pdf/empfehlung_pdf Stand: 15.03.2010

[23] Verband Deutscher Rentenversicherungsträger. Phaseneinteilung in der neurologischen Rehabilitation. Rehabilitation 1995; 34: 119-127

[24] Freidel K, Leisse M. Wieviel FIM entspricht soviel SINGER? Übereinstimmung und Umrechnung der Funktionsassessments SINGER und FIM. In: Deutsche Rentenversicherung Bund, (Hrsg.) Tagungsband zum 20. Rehabilitationswissenschaftlichen Kolloquium. DRV Schriften 2011; 93: 90-93

[25] Rabin R, de Charro F. EQ-D5: a measure of health status from the EuroQol Group. Annals of Medicine 2001; 33: 337-343

[26] Devlin NJ, Krabbe PFM. The development of new research methods for the valuation of EQ-5D-5L. Eur J Health Econ 2013; 14 (Suppl 1): S1-S3

[27] Banks JL, Marotta CA. Outcomes validity and reliability of the modified rankin scale: implications for stroke clinical trials. Stroke 2007; 38: 1091-1096

[28] Teasdale G, Jennett B. Assessment of coma and impaired consciousness. A practical scale. Lancet 1974; 2: 81-84

[29] Leonhart R. Effektgrößenberechnung bei Interventionsstudien. Rehabilitation 2004; 43: 241-246

[30] Cohen J. Statistical power analysis for the behavioral sciences. 2nd ed. Hillsdale (New Jersey): Erlbaum; 1988

[31] Wirtz M. Über das Problem fehlender Werte: Wie der Einfluss fehlender Informationen auf Analyseergebnisse entdeckt und reduziert werden kann. Rehabilitation 2004; 43: 109-115
[32] Schafer JL, Graham JW. Missing data: our view of the state of the art. Psychol Meth 2002; 7: 147-177

[33] Bortz J. Statistik für Sozialwissenschaftler. 5. vollst. überarb. Aufl. Berlin, Heidelberg: Springer; 1999

[34] Faller H, Haaf HG, Kohlmann T et al. Orientierungshilfen und Empfehlungen für die Anlage, Durchführung und Interpretation von Studien in der Rehabilitationsforschung. In: Verband Deutscher Rentenversicherungsträger., (Hrsg.). Förderschwerpunkt „Rehabilitationswissenschaften“ - Empfehlungen der Arbeitsgruppen „Generische Methoden“, „Routinedaten“ und „Reha-Ökonomie“.1999; 13-52 Im Internet http://www.deutsche-rentenversicherung.de/nn_10540/ SharedDocs/de/Inhalt/Zielgruppen/01__sozialmedizin_ forschung/03_reha_wissenschaften/dateianhaenge/empfehlung_ pdf, templateld $=$ raw property = publicationFile.pdf/empfehlung_pdf; Stand: 15.03 .2010

[35] Reuther P, Bergermann U. Ergebnisse der Phase-C-Rehabilitation im ambulanten Setting-Erfahrungen eines RehaTeams mit 200 Patienten in 6 Jahren. Neurol Rehabil 2015; 21: 275-281

[36] Deck R, Raspe H. Nachsorgeempfehlungen und ihre Umsetzung im Anschluss an die Rehabilitation. In: Deck R, Glasner-Möller N, Mittag O, (Hrsg.). Rehabilitation und Nachsorge. Lage: Jacobs; 2004: 55-70

[37] Waanders R, Fischer J, Girardi P et al. Outcome nach ambulanter neurologischer Rehabilitation: Eine populationsbasierte prospektive Kohortenstudie. J Neurol Neurosurg Psychatry 2004; 5: 24-30

[38] Deck R, Walther AL, Staupendahl A et al. Einschränkungen der Teilhabe in der Bevölkerung - Normdaten für den IMET auf der Basis eines Bevölkerungssurveys in Norddeutschland. Rehabilitation 2015; 54 : 402-408

[39] Schumacher M, Schulgen G. Methodik klinischer Studien. Methodische Grundlagen der Planung, Durchführung und Auswertung. 3. Auflage Berlin, Heidelberg: Springer; 2002 